\begin{tabular}{ll}
\hline \hline MINING AND METALLURGY INSTITUTE BOR & ISSN: 2334-8836 (Štampano izdanje) \\
UDK: 622 & ISSN: 2406-1395 (Online) \\
\hline \hline
\end{tabular}

Slavica Miletic ${ }^{*}$ Dejan Bogdanovic***, Dragan Milanovic ${ }^{*}$

\title{
ADVANTAGES OF IMPLEMENTATION \\ THE PROCESS MODEL FOR SUSTAINABLE BUSINESS OPERATIONS OF MINING COMPANIES ${ }^{* * *}$
}

\begin{abstract}
Process approach is the basic element for integration the all similar requirements of the integrated management system (ISM) standard and stakeholders.

Previous studies have shown that the process model of the ISM is the most represented in the Serbian companies. Implementation of the process model in mining company improves the company performances.

This work analyzes the most important advantages achieved in implementation the process model and the appropriate criteria are defined for their evaluation. The AHP method was used to evaluate the advantages of process model. The results differentiate the most important advantages of the process model achieved by sustainable business operations of mining companies on the basis of competitiveness based on eco-innovations.
\end{abstract}

Keywords: process model, sustainable business operation, AHP method

\section{INTRODUCTION}

According to definition of the standard ISO 9000, the process is a set of interrelated or interacting activities that transform inputs into outputs (SRPS ISO 9000:2008). Each interrelated mining activity in a sustainable business operation that transforms inputs into outputs is seen as a process with the aim of creating the value for customer. It is common in the mining processes that the output elements from one process (excavation) present the input elements (drilling) of the following processes. The process approach is when these actions and the related necessary resources are managed as a pro- cess. As the mining company would be able to satisfy the customer demands, they should be analyzed and to recognize and establish each process. Management of the mining company is aimed to operate responsibly so that the processes should have the "owners" of process or persons who are responsible for these processes.

Process approach is the basis of implementation the integrated management system or management standards. The need for more efficient management by simplifying the job (quality control) and development of information technologies have shaped the

\footnotetext{
* Mining and Metallurgy Institute Bor, Zeleni Bulevar 35, 19210 Bor, Serbia, e-mail: slavica.miletic@irmbor.co.rs

** Technical Faculty Bor, University of Belgrade, V.J. 12, 19210 Bor, Serbia

*** Research was funded by the Ministry of Education and Technological Development as a part of the Project TR 33023: Development the Flotation Concentration Technology of Copper Ore and Precious Metals in Order to Achieve the Technological Results
} 
process approach. The essence of the process model is to improve the way of sustainable business, to make more efficient and effective the overall business. To introduce a business that suits satisfying the requirements of stakeholders, a business that corresponds to the modern trends, the modern management business.

Modern management is a quality management, identification and understanding the process. Therefore, the mining companies need to establish a catalog of the process where the reciprocal links of each process are established with related resources and other processes. Management of mining company has to make the Matrix of responsibilities of each organizational unit for given processes where the owners of these processes are pre-determined.

The purpose of process approach is improvement and optimization of sustainable business in order to obtain the best possible result with minimum investment of resources

The process model is the basic element of integration the all requirements of IMS and all interested parties (stakeholders). The process approach represents an important new management approach due to the integration of identical and specific requirements of standard and interested parties. The similarity in context of the standards ISO 9001, ISO 14001, OHSAS 18001 and ISO 2200 indicate the integration of standards in the aim of customer satisfaction, what is the essence of the process model.

ISO 9001 Quality Management System (QMS) is the "core of integration." QMS does not include the specific requirements of the other standards but already has the ability to connect with its quality system the requirements with the other systems that are similar. Quality management system focuses on providing the quality results to satisfy the needs of interested parties which have similarities with the other integrated standards.

As it is shown in Figure 1, the inpu elements arise from the user requirements. During realization of the product, the permanent measurements, analyses and improvement of the product quality are made with the management of resources. For continuous improvements of the quality management system, a responsible person is the leader of management according to the new standard ISO 9001:2015 as to improve the user requirements.

Trends of modern management follow the PDCA (Plan, Do, Check, Act, Approach) cycle:

Plan: establish the objectives and processes necessary to deliver the results in accordance with the customer requirements, purpose and established strategy of organization.

Do: apply the processes related to the customer requirements.

Check: Supervise, measure the processes and products according to demand and objectives of the company, a permanent presentation of the results

Work (improve): follow the actions for continuous process improvement.

The existence of a clear and precise process model is a prerequisite for effective implementation of requirements of the new organizational - management standards and establishment of an integrated management system [2]. Implementation of the process model identifies: constant improvement of processes based on objective measurement, measurement the process performances, needs of process consideration with added value and increase the satisfaction of stakeholders [3]. Principles for access to the process model are explained in the work paper "Process Model for Sustainable Business of Mining Companies" [4]. 


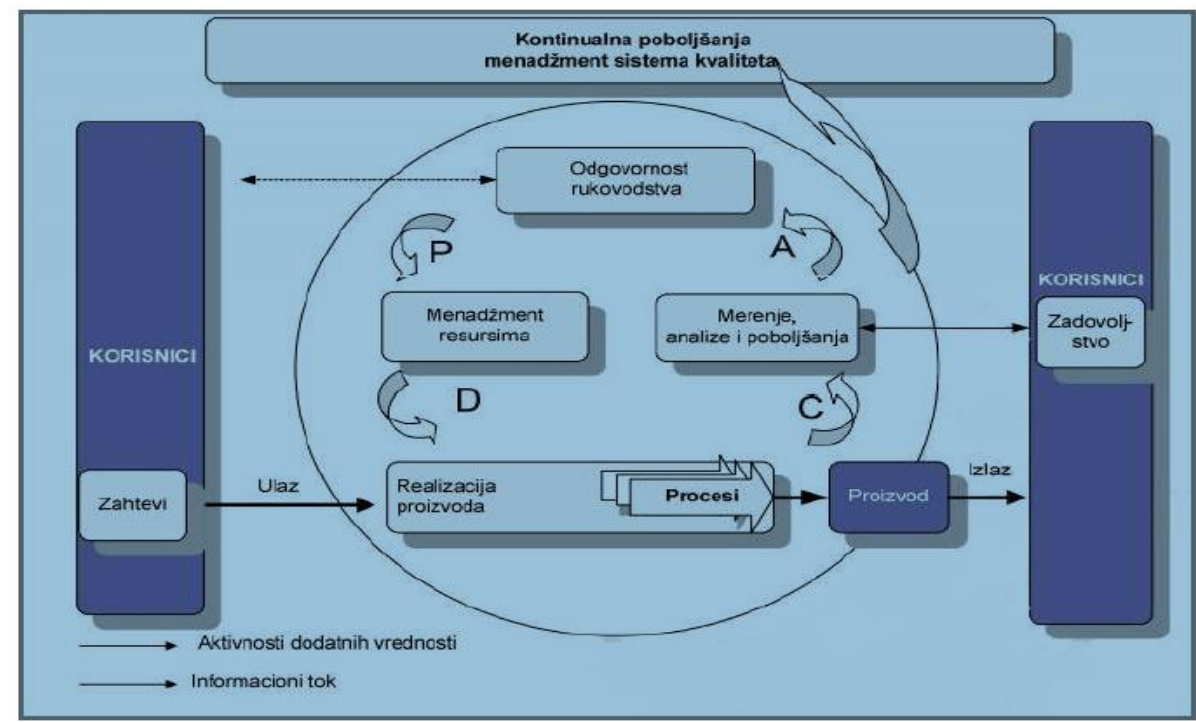

Figure 1 Model of quality management system based on processes [1]

The aim of work is to differentiate the most important benefits by implementation the process models, to evaluate in relation to the defined criteria using the AHP (Analytical Hierarchy Process) method. Assessment the benefits by the multi-criteria analysis for sustainable operations of mining companies shows where the company will be positioned for several years, the performances, profit, cost, maximizing the product quality, and the most important - the customer satisfaction.

\section{BENEFITS OF IMPLEMENTATION THE PROCESS MODEL}

Studies show that the representation of the process model is $96.23 \%$ in our companies. ISO 9001:2015, which should be valid from $15^{\text {th }}$ September 2018, represents highlighting of the process model.

The process model has its own characteristics which are reflected through application the process approach. It integrates $\mathrm{N}$ system and QMS, EMS System (environment protection system), OHSAS (health and safety system) and HACCP (food safety system). The essence of these standards is in management of processes.

The most important advantages of the process model in sustainable business operation of mining companies are:

- Effective external and internal communication (Alternative 1) - Process model enables to the mining companies to effectively communicate with customers and in terms of:

- Information on services and product,

- Contract and order replacements,

- Feedback on services and product including complaints and appeals.

Managers and leaders of the mining companies are required to establish an appropriate communication process within the business at the level of effectiveness the quality management system.

- Providing the resources (Alternative 2) - Process approach allows the company to provide the necessary resources that are required: for continuous improvement, implementation, es 
tablishment and maintenance the management system.

- Improvement of performances in the planning and management processes (Alternative 3) - Process model enables the company to plan and manage the processes in relation to determination the requirements of products and services. The focus is on increasing the customer satisfaction and improvement the performances of the company in order to support sustainable business operations of mining companies.

- Effective implementation the changes and additions to ISM (Alternative 4) -Process approach enables the mining companies, due to their specific activities and improvement the green economy and clean production processes, to efficiently and, as required by the interested parties, to make changes and additions of ISM.

- Lower costs (Alternative 5) - By implementation the process model, the mining companies plan the processes, apply processes as to respond to the user requirements, check the processes and constantly present the results and improve processes by reducing the costs of products and services.

- Monitoring and process measurement (Alternative 6) - Process approach allows continuous monitoring and process measurement, and this is the primary for the mining company. Accordingly, the specific requirements of standard are confirmed as well as the specific user requirements. The process assessment by this alternative runs the company to the sustainable development.

- Monitoring the overall business (Alternative 7) - Process model of the mining companies enables monitoring the overall business, what gives the guidance to the company. With this approach, monitoring the overall business as an integrated system of the process in which all segments of the organization process (development, procurement, production preparation, production, sales, marketing) function as a whole (integrated) system. So, to yield the efficient and effective organization that functions as a mechanism.

\section{DEFINING THE CRITERIA FOR EVALUATION THE BENEFITS}

The alternatives are evaluated by the criteria and they are the most important in the process of multi-criteria decision-making.

Positioning (Criterion C1). This criterion plays an important role in evaluation of the process model implementation (PM). By implementation, PM comes to better positioning of the mining company.

Profit (Criterion C2) - Process model ISM is in the focus of satisfaction the customer, stakeholders and for profit, so that this criterion has great influence on the process model advantages. Profit or gain for all stakeholders is the highest priority. Realizing the profit, all users and stakeholders become satisfied and mining organizations are sustainable.

User satisfaction (Criterion C3): Every organization depends on satisfaction of its users. Therefore, the organization is forced to have perception for their current and future needs. Constant monitoring of customer requirements, overcoming the expectations of users and improving the business practices is the easiest way to the sustainability of the mining company.

Maximizing the quality of products and services (Criterion C4): This criterion brings maximizing the quality of products and services what increase the customer satisfaction.

The involvement of employees (Criterion C5): The organization must include the employees for effective implementation the 


\section{RESULT OF SELECTION THE PM ADVANTAGES}

quality management system, implementation the operational activity of the process and determining the compliance of products and services. The employees are part of an organization where they meet and integrate with organization. It is important to develop a working environment and evaluate the knowledge, behavior and skills.

Cost reduction (Criterion C6): Cost reduction as a criterion is very important for the company survival, its growth, development and improvement of the quality management system.

Risk Reduction (Criterion C7): Risk reduction criterion is of particular importance for sustainable operations of the mining companies. By risk reduction, the negative effects are prevented, the results of business are improved and the effectiveness of the quality management system increases.

Applicability of the process model (Criterion C8): ISO Standard 9001:2015 supports the process model. Mining companies have complex processes so that the process model is the optimal model [5].
Over time, the multi-criteria decisionmaking methods MCDM were applied to solve a lot of problems [6]. They have this ability to rank the alternatives based on a predefined set of specific criteria that are conflict [7]. For ranking of alternatives, the AHP method is applied whose creator Thomas Saaty, which "represents a powerful tool of leaders (decision makers) where more alternative solutions" are offered [8], and the software Criterium Decision Plus was used for calculation.

Later works with the applied AHP method are: Selection of an optimal model of ISM of the mining companies [5], ranking the indicators of sustainability for decision making in the mining companies [9], evaluation and selection of personnel using the MCDM method [10], management model of investment projects for opening the coal open pits [11] and others.

In this method, the first step is to define the multi-dimensional hierarchical structure of objectives, criteria and alternatives in Figure 1.

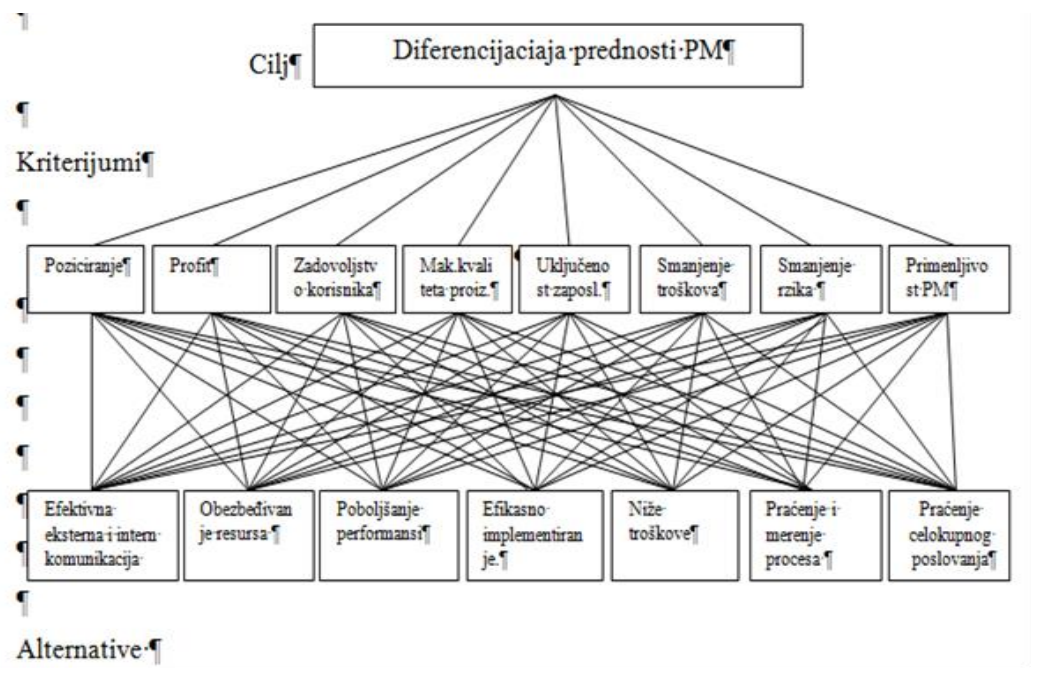

Figure 2 Structuring an advantage differentiation of the Process Model 
To determine the weighting coefficient of criteria with the help of comparison scale, given in Table 1 . Tables 2 and 3 show the comparison results.

Table 1 Comparing scale of decision elements

\begin{tabular}{|l|l|}
\hline Dominance & Rating \\
\hline Description & 1 \\
\hline Equally & 3 \\
\hline Poor domination & 5 \\
\hline Strong domination & 7 \\
\hline Very strong domination & 9 \\
\hline Absolute domination & \\
\hline $2,4,6,8$ are intermediate value \\
\hline
\end{tabular}

Table 2 Defining of weighting coefficient criteria

\begin{tabular}{|l|l|l|l|l|l|l|l|l|}
\hline Criteria & C1 & C2 & C3 & C4 & C5 & C6 & C7 & C8 \\
\hline C1 & 1 & $1 / 2$ & 3 & 2 & 4 & $1 / 3$ & $1 / 2$ & 4 \\
\hline C2 & & 1 & 2 & 3 & 5 & $1 / 2$ & $1 / 2$ & 4 \\
\hline C3 & & & 1 & 2 & $1 / 3$ & $1 / 7$ & $1 / 7$ & $1 / 3$ \\
\hline C4 & & & & 1 & 3 & $1 / 2$ & $1 / 3$ & $1 / 3$ \\
\hline C5 & & & & & 1 & $1 / 7$ & $1 / 7$ & $1 / 3$ \\
\hline C6 & & & & & & 1 & 1 & 3 \\
\hline C7 & & & & & & & 1 & 3 \\
\hline C8 & & & & & & & & 1 \\
\hline
\end{tabular}

Table 3 Results of weighting coefficient criteria

\begin{tabular}{|l|l|l|l|l|l|l|l|l|}
\hline Criteria & C1 & C2 & C3 & C4 & C5 & C6 & C7 & C8 \\
\hline $\begin{array}{l}\text { Weighting } \\
\text { coefficients }\end{array}$ & $\mathbf{0 . 1 3 0}$ & $\mathbf{0 . 1 6 4}$ & $\mathbf{0 . 0 4 5}$ & $\mathbf{0 . 0 6 1}$ & $\mathbf{0 . 0 4 0}$ & $\mathbf{0 . 2 4 1}$ & $\mathbf{0 . 2 3 4}$ & $\mathbf{0 . 0 8 4}$ \\
\hline $\begin{array}{l}\text { Consistency } \\
\text { degree }\end{array}$ & 0.097 \\
\hline
\end{tabular}

Further step of the AHP method is to relative to all eight criteria defined in Tacompare the advantages (alternatives) bles 5-12.

Table 4 Comparison of alternatives in relation to criterion C1

\begin{tabular}{|l|l|l|l|l|l|l|l|}
\hline Alternatives & A1 & A2 & A3 & A4 & A5 & A6 & A7 \\
\hline A1 & 1 & 1 & $1 / 3$ & 5 & $1 / 2$ & $1 / 2$ & 4 \\
\hline A2 & & 1 & $1 / 3$ & 7 & 1 & 2 & 6 \\
\hline A3 & & & 1 & 8 & 1 & 2 & 5 \\
\hline A4 & & & & 1 & $1 / 7$ & $1 / 5$ & $1 / 5$ \\
\hline A5 & & & & 1 & 2 & 1 \\
\hline A6 & & & & & 1 & 1 \\
\hline A7 & & & & & & 1 \\
\hline Consistency degree & & & & & & & \\
\hline
\end{tabular}


Table 5 Comparison of alternatives in relation to criterion $C 2$

\begin{tabular}{|l|l|l|l|l|l|l|l|}
\hline Alternatives & A1 & A2 & A3 & A4 & A5 & A6 & A7 \\
\hline A1 & 1 & 2 & $1 / 3$ & 3 & $1 / 3$ & $1 / 5$ & $1 / 2$ \\
\hline A2 & & 1 & 1 & 3 & $1 / 3$ & $1 / 3$ & $1 / 2$ \\
\hline A3 & & & 1 & 5 & 1 & 2 & $1 / 4$ \\
\hline A4 & & & & 1 & $1 / 5$ & $1 / 7$ & $1 / 9$ \\
\hline A5 & & & & 1 & $1 / 2$ & $1 / 3$ \\
\hline A6 & & & & & 1 & $1 / 2$ \\
\hline A7 & & & & & & 1 \\
\hline \multicolumn{2}{l}{ Consistency degree } & & & & & & \\
\hline
\end{tabular}

Table 6 Comparison of alternatives in relation to criterion C3

\begin{tabular}{|l|l|l|l|l|l|l|l|}
\hline Alternatives & A1 & A2 & A3 & A4 & A5 & A6 & A7 \\
\hline A1 & 1 & 1 & 2 & 2 & 2 & 2 & $1 / 2$ \\
\hline A2 & & 1 & $1 / 2$ & 1 & $1 / 2$ & 2 & $1 / 2$ \\
\hline A3 & & & 1 & 3 & $1 / 2$ & 1 & 2 \\
\hline A4 & & & & 1 & $1 / 3$ & $1 / 3$ & $1 / 3$ \\
\hline A5 & & & & & 1 & 3 & 1 \\
\hline A6 & & & & & 1 & 1 \\
\hline A7 & & & & & & 1 \\
\hline Consistency degree & & & & & & & \\
\hline
\end{tabular}

Table 7 Comparison of alternatives in relation to criterion $C 4$

\begin{tabular}{|l|l|l|l|l|l|l|l|}
\hline Alternatives & A1 & A2 & A3 & A4 & A5 & A6 & A7 \\
\hline A1 & 1 & 1 & 1 & $1 / 2$ & 2 & 1 & 1 \\
\hline A2 & & 1 & 4 & 2 & 3 & $1 / 2$ & $1 / 3$ \\
\hline A3 & & & 1 & $1 / 3$ & 1 & 1 & $1 / 5$ \\
\hline A4 & & & & 1 & 1 & $1 / 3$ & $1 / 3$ \\
\hline A5 & & & & 1 & $1 / 2$ & $1 / 3$ \\
\hline A6 & & & & & 1 & $1 / 2$ \\
\hline A7 & & & & & & 1 \\
\hline Consistency degree & & & & & & & \\
\hline
\end{tabular}

Table 8 Comparison of alternatives in relation to criterion $C 5$

\begin{tabular}{|l|l|l|l|l|l|l|l|}
\hline Alternatives & A1 & A2 & A3 & A4 & A5 & A6 & A7 \\
\hline A1 & 1 & 3 & 2 & $1 / 3$ & 3 & 1 & 1 \\
\hline A2 & & 1 & $1 / 2$ & 1 & $1 / 2$ & $1 / 3$ & $1 / 3$ \\
\hline A3 & & & 1 & 1 & 1 & $1 / 2$ & 1 \\
\hline A4 & & & & 1 & $1 / 2$ & 1 & $1 / 2$ \\
\hline A5 & & & & 1 & $1 / 2$ & $1 / 3$ \\
\hline A6 & & & & & 1 & 1 \\
\hline A7 & & & & & & 1 \\
\hline Consistency degree & & & & & & & \\
\hline
\end{tabular}


Table 9 Comparison of alternatives in relation to criterion C6

\begin{tabular}{|l|l|l|l|l|l|l|l|}
\hline Alternatives & A1 & A2 & A3 & A4 & A5 & A6 & A7 \\
\hline A1 & 1 & 1 & $1 / 3$ & $1 / 2$ & $1 / 5$ & 1 & 2 \\
\hline A2 & & 1 & $1 / 5$ & $1 / 4$ & $1 / 9$ & $1 / 3$ & $1 / 3$ \\
\hline A3 & & & 1 & 2 & $1 / 3$ & 1 & $1 / 2$ \\
\hline A4 & & & & 1 & $1 / 5$ & 1 & $1 / 3$ \\
\hline A5 & & & & & 1 & 5 & 3 \\
\hline A6 & & & & & 1 & $1 / 2$ \\
\hline A7 & & & & & & 1 \\
\hline Consistency degree & & & & & & & \\
\hline
\end{tabular}

Table 10 Comparison of alternatives in relation to criterion $C 7$

\begin{tabular}{|l|l|l|l|l|l|l|l|}
\hline Alternatives & A1 & A2 & A3 & A4 & A5 & A6 & A7 \\
\hline A1 & 1 & 2 & $1 / 2$ & 1 & $1 / 7$ & 1 & $1 / 5$ \\
\hline A2 & & 1 & $1 / 2$ & 2 & $1 / 7$ & $1 / 5$ & $1 / 7$ \\
\hline A3 & & & 1 & 3 & $1 / 5$ & $1 / 3$ & $1 / 5$ \\
\hline A4 & & & & 1 & $1 / 5$ & $1 / 3$ & $1 / 7$ \\
\hline A5 & & & & & 1 & 7 & 5 \\
\hline A6 & & & & & 1 & $1 / 3$ \\
\hline A7 & & & & & & 1 \\
\hline Consistency degree & & 0.094 & & & & \\
\hline
\end{tabular}

Table 11 Comparison of alternatives in relation to criterion $C 8$

\begin{tabular}{|l|l|l|l|l|l|l|l|}
\hline Alternatives & A1 & A2 & A3 & A4 & A5 & A6 & A7 \\
\hline A1 & 1 & 1 & 1 & $1 / 2$ & $1 / 3$ & $1 / 3$ & 1 \\
\hline A2 & & 1 & 1 & 1 & 1 & 1 & $1 / 4$ \\
\hline A3 & & & 1 & $1 / 3$ & 1 & 1 & $1 / 3$ \\
\hline A4 & & & & 1 & $1 / 3$ & 1 & $1 / 3$ \\
\hline A5 & & & & & 1 & 3 & $1 / 2$ \\
\hline A6 & & & & & & 1 & $1 / 2$ \\
\hline A7 & & & & & & 1 \\
\hline \multicolumn{2}{l|}{ Consistency degree } & & & & & & \\
\hline
\end{tabular}

The obtained results of ranking after calculation are shown in Table 12. The results show that the most important advantages of the procedural model implementation are in the following order: lower costs alternative A5, monitoring the overall business A7, improvement the performances in the plan ning and management processes alternative $\mathrm{A} 3$, monitoring and measuring the process alternatives A6, effective external and internal communication alternative A1, supplying the resources alternatives $\mathrm{A} 2$, and in the end the effective implementation of changes and additions of ISM alternative A4. 
Table 12 Final ranking

\begin{tabular}{|c|l|c|}
\hline $\begin{array}{c}\text { Ord. } \\
\text { No. }\end{array}$ & \multicolumn{1}{|c|}{ PM advantages per importance } & \multicolumn{1}{|c|}{ Result } \\
\hline 1. & A5 (lower costs) & 0.282 \\
\hline 2. & A7 (monitoring the overall business) & 0.207 \\
\hline 3. & $\begin{array}{l}\text { A3 (improvement the performances in the planning and man- } \\
\text { agement processes) }\end{array}$ & 0.139 \\
\hline 4. & A6 (monitoring and measuring the process) & 0.127 \\
\hline 5. & A1 (effective external and internal communication) & 0.097 \\
\hline 6. & A2 (supplying the resources) & 0.082 \\
\hline 7. & A4 (effective implementation of changes and additions of ISM) & 0.065 \\
\hline
\end{tabular}

Figure 2 shows the structure of benefit differentiation the implementation of process model with the weighting coeffi

cients obtained in calculation by hierarchy of decision making.

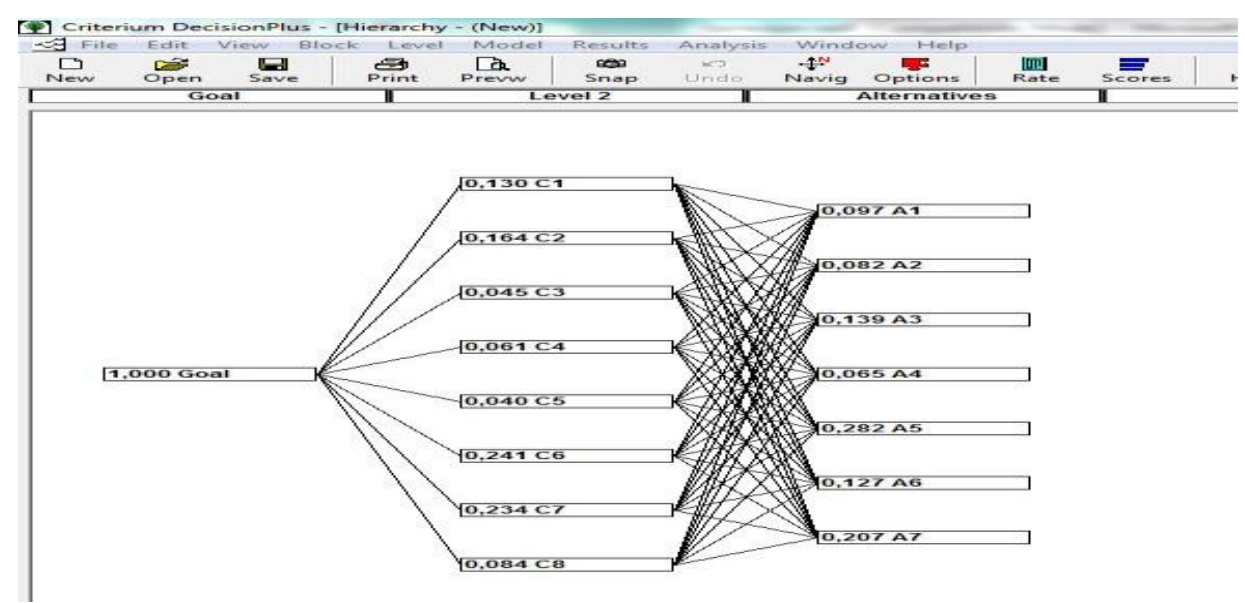

Figure 2 Results of PM implementation advantages by hierarchy of decision making

\section{ANALYSIS OF THE OBTAINED \\ RESULTS}

Analysis of the results includes eight criteria and their impact on ranking the advantage of implementation the process model, and the advantage (alternative) by importance.

In criteria analyzing, the most important are the weighting coefficients of criteria because it is their measure that affects the results of ranking the alternatives, or advantages of implementation the process model.
Table 3 shows that criteria could be divided into three groups:

- The first group includes the criteria C6 - cost reduction, which has the greatest impact on the results of ranking because its weighting coefficient is 0.241, and criterion C7 - risk reduction with a coefficient of 0.234 . Cost reduction affects from $24.1 \%$ to the ranking of implementation benefits the 
process model in relation to the other criteria. While, the criterion of risk reduction affects $23.4 \%$, so that these two criteria have the greatest impact on ranking the PM implementation benefits PM to determine their importance.

This analysis shows that ranking the benefits of PM implementation of the mining company is the most important cost reduction and risk reduction what is improved by the company growth and development, reducing the negative effects and improving the effectiveness of the quality management system.

- The second group is generated by two criteria: criterion $\mathrm{C} 1$-profit with weighting coefficient of 0.164 which, $16.4 \%$ affects the obtained result and criterion C2-positioning, which carries the weighting coefficient of 0.130 , so that the result is affected by $13 \%$. The results of ranking the benefits of PM implementation show how important are the criteria profit and positioning for the mining company. Well positioned mining company brings higher profit and vice versa higher profit enables better positioning to the company. So that the PM imple-mentation of the mining company enables improvement the satisfaction of the end user and leads the company to the sustainable business.

- The third group includes: criteria C8 applicability of the process model with coefficient of 0.084 which affects the result by $8.4 \%$; Criterion $\mathrm{C} 4$ - maximization the quality of products and services with the weighting coefficient of 0.061 in affecting the obtained result 6.1\%; Criterion C3 - user satisfaction with the weighting coefficient of 0.045 to the obtained result affects $4.5 \%$ and criterion $\mathrm{C} 4$ - involvement of employees with the weighting coefficient of 0.040 , which means that it affects with $4.0 \%$ to the ranking of results. This analysis shows that the applicability of the process model for the complex process of mining company with maximizing the quality of products and services in involvement of employees comes to improvement the satisfaction of the end user and all stakeholders.

Analyzing the most important alternative implementation to the process model, it starts from the most important alternative. This is the alternative A5 (lower costs) with the highest value of results 0.282 . This alternative is focused on cost reduction of the company. Applying the PDCA cycle: process planning; realization of products; verification and presentation of results and action (improvement) is followed by reduction of total costs.

The second most important is the alternative A7 (monitoring the entire business) which carries the value of results 0.207 . By this approach, the managers of the mining company have the ability to monitor the entire business from procurement to sales and marketing as one mechanism that operates efficiently and effectively.

On the third place is the alternative A3 (performance improvement in the planning and management processes) with a degree of consistency 0.139 . This alternative refers to the established requirements of products and services and in the focus of increasing the end user satisfaction.

On the fourth place is the alternative A6 (monitoring and measurement of processes) with a degree of consistency 0.127 . Monitoring and measurement of processes in the mining company confirms the specific requirements of standard and established requirements of the users.

On the fifth place of the most important advantages of PM is the alternative A1 (effective external and internal communication) which the value of results 0.097 .

The alternative 1 enables to the managers of the mining company: 
- effective communication with internal and external users about the product and services,

- agreement on contracts and change of order,

- feedback on services and products including the complaints and appeals

- establish the communication within the business at the level of effectiveness the quality management system.

The sixth place is occupied by the alternative A2 (supplying the resources) with a degree of consistency of 0.082 . This alternative is aimed, unlike the others, to provide the necessary resources for process development for company to be kept up.

On the seventh place of importance is the alternative A4 (effective implementation of change and addition the ISM-a), which has the value of results of 0.065 . The alternative $\mathrm{A} 4$, due to the specific activities, green economy, clean production and satisfying the user requirements, enables to the mining company fast and efficient addition and change the ISM.

\section{CONCLUSION}

In this work, one of the multicriteria method AHP was applied to rank the benefits of PM by importance with the aim of helping the managers for selecting the optimal model ISM. The process model is supported by the ISO standard 9001:2015, which prompted the authors to analyze its advantages by importance.

Based on calculation by the AHP, the ranked benefits by importance were obtained. Analyzing the benefits resulted into the final ranking: lower costs (Alternative 5) took the first place, the second place was taken by the alternative of monitoring the overall business (Alternative A7), the third place is improvement in the planning and management processes (Alternativa 3), the fourth place is the alternative A6 - monitoring and measuring of processes, and on the fifth place is the Alternative A1 - effective external and internal communication, and on the sixth place is the Alternative A2 - supplying the resources, while the last place is the effective implementation of addition and change the ISM (Alternative A4). It can be concluded from rom this analysis that lower costs and monitoring the overall business are the most important advantages of PM, where the mining companies are run to a competitive advantage. Analyzing the alternatives leads to an interesting conclusion and that all are related and integrated work.

The most influential criteria for complete rankings the PM advantages are: cost reduction (criterion 6) and criterion $\mathrm{C} 7$-risk reduction. By identification of these two criteria: cost reduction and risk reduction are crucial in managing the mining companies. These two criteria can help to reduce risk and better strategic development of the company. A well-chosen strategy of the mining companies is the key to the success of the company.

Such made analysis of the implementtation benefits of the process model serve to the managers as an aid to select the optimal form of ISM, to lead the mining company to the increased profit, good ranking, competitive advantage based on eco-innovation, green economy and that all integrated represents an improvement of satisfaction the all stakeholders.

\section{REFERENCES}

[1] Helta M., Design of the Quality Management System. First Edition, University Singidunum, Belgrade, 2012 (in Serbian)

[2] Vulović S., Development of the General Model for Implementation the Integrated Management System Based on Risk Assessment in the Organization Processes. Doctoral Dissertation, University of Novi Sad, Faculty of Technical Sciences in Novi Sad, 2015 (in Serbian) 
[3] Rajković D., Integrated Management System in Small and Medium-sized Enterprises, Doctoral Dissertation, University in Kragujevac, Faculty of Mechanical Engineering

Kragujevac, 2010 (in Serbian)

[4] Miletić S., Bogdanović D., Velinov V., Process Model for Sustainable Business of Mininig Companies. 48th International October Conference on Mining and Metallurgy, Technical Faculty in Bor, University of Belgrade and Mining and Metallurgy Institute Bor, (2016) 232-235. ISBN: 978-866305-047-1.

[5] Miletić S., Bogdanović D., Paunković Dž., Selection of the Optimal Model of Integrated Sustainable Management System in the Mining Companies. Journal of Mining and Metallurgy Engineering Bor, 2, (2015) 182-192.

[6] Karabasevic D., Zavadskas E. K., Turskis Z., Stanujkic D., The Framework for the Selection of Personnel Based on the SWARA and ARAS Methods Under Uncertainties. Informatica, 27(1), (2016) pp. 49-65.

[7] Karabašević D., Defining the Criteria for Evaluating of Candidates in the Recruitment Process and Selection of
Staff Using the Method of MultiCriterion Decision-Making. Doctoral Dissertation, Faculty for Management Zajecar, University "John Neizbit", Belgrade, 2016 (in Serbian)

[8] Winston W., Albright C., Practical Management Science, Revised Third Edition, London: Thomson SouthWestern, (2008) 484.

[9] Miletić S., Bogdanović D., Paunković Dž., Evaluation the Sustainability Indicators for Decision Making in the Mining Companies, Megatrend revija, University "John Neizbit", Belgrade, 13(2), (2016) 83-96 (in Serbian)

[10] Bogdanović D., Miletić S., Personnel Evaluation and Selection by Multicriteria Decision Making Method. Journal of Economic Computation and Economic Cybernetics Studies and Research, 48(3), (2014) 179-196.

[11] Cvjetko S., Management Model of Investment Projects for Opening the Open Pit Coal Mines. Doctoral Dissertation, University of Belgrade, Faculty of Mining and Geology, 2015 (in Serbian)

[12] Normative Documents

[13] SRPS ISO 9000:2008. 